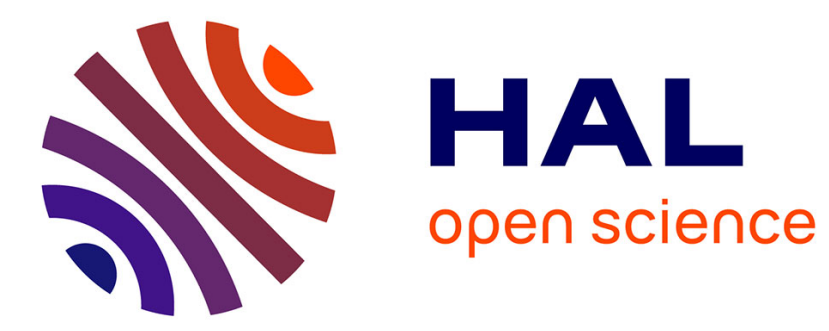

\title{
A single indicator of noxiousness for people and ecosystems exposed to stable and radioactive substances
}

K. Beaugelin-Seiller, R. Gilbin, S. Reygrobellet, J. Garnier-Laplace

\section{To cite this version:}

K. Beaugelin-Seiller, R. Gilbin, S. Reygrobellet, J. Garnier-Laplace. A single indicator of noxiousness for people and ecosystems exposed to stable and radioactive substances. Environmental Pollution, 2019, 249, pp.560-565. 10.1016/j.envpol.2019.03.061 . hal-02507817

\section{HAL Id: hal-02507817 \\ https://hal.science/hal-02507817}

Submitted on 22 Oct 2021

HAL is a multi-disciplinary open access archive for the deposit and dissemination of scientific research documents, whether they are published or not. The documents may come from teaching and research institutions in France or abroad, or from public or private research centers.
L'archive ouverte pluridisciplinaire HAL, est destinée au dépôt et à la diffusion de documents scientifiques de niveau recherche, publiés ou non, émanant des établissements d'enseignement et de recherche français ou étrangers, des laboratoires publics ou privés.

\section{(c) (1) $\$$}

Distributed under a Creative Commons Attribution - NonCommerciall 4.0 International 


\section{A single indicator of noxiousness for people and ecosystems exposed to stable and 2 radioactive substances}

3 Karine Beaugelin-Seiller ${ }^{1 *}$, Rodolphe Gilbin ${ }^{2}$, Sophie Reygrobellet ${ }^{3}$ and Jacqueline

4 Garnier-Laplace ${ }^{4}$

5 Institut de Radioprotection et de Sûreté Nucléaire, ${ }^{1}$ PSE-ENV/SRTE/LECO, ${ }^{2} \mathrm{PSE}-$

6 ENV/SRTE, ${ }^{3}$ PSE-ENV/SEREN/LEREN, ${ }^{4}$ PSE-ENV, St Paul les Durance (13115)

$7 \quad$ France

$8 *$ Address correspondence to karine.beaugelin@irsn.fr

10 Abstract

11 Inspired by methods used for life cycle impact assessment (LCIA), we constructed a

12 series of indicators to appreciate the noxiousness of radioactive materials and wastes for

13 human and ecosystem health. According to known potential human health and ecological

14 effects of such materials, six main impact categories were considered to initiate the

15 development of the method: human cancer and non-cancer effects vs. ecotoxicity,

16 considering both chemotoxicity and radiotoxicity. For ecosystems, the noxiousness

17 indicator is based on the concept of Potentially Affected Fraction (PAF), used as a

18 damage indicator at the ecosystem level. The PAF express the toxic pressure on the

19 environment due to one substance. It has been enlarged to mixtures of substances as

20 multi-substances PAF (ms-PAF), and applied to a mix of stable and radioactive

21 substances. Combining ecotoxicity data and a simplified model of exposure of fauna and 
22 flora, we proposed a chemotoxicity indicator and a radiotoxicity indicator, ultimately aggregated into a single indicator simply by addition.

24 According to acknowledged practices in LCIA and corresponding available data, we

25 suggested implementing to human health an approach similar to that applied to

26 ecosystems. We produced eigth basic indicators combining effects categories (cancer and

27 non cancer), exposure pathways (ingestion and inhlation) and substances (chemicals and

28 radionuclides). The principle of additivity supporting the whole proposed approach

29 allows their complete aggregation into a single indicator also for human health. Different

30 source terms may be then easily directly compared in terms of human and ecological

31 noxiousness.

32 Applied to the time evolution of a High Level radioactive Waste (HLW), the method

33 confirmed over 1 million years the dominance of the radiotoxicity in the noxiousness of

34 the material for both humans and environment. However there is a change with time in

35 the ranking of the most noxious substances, with stable metals contribution going

36 progressively up. Finally, the HLW global noxiousness, integrating human health and

37 ecological aspects, was assesed through time at three stages and showed a temporal

38 decrease as expected from the dominance of the radiotoxicity.

39

40 Capsule: The ecological noxiousness of chemicals and radionuclides can be expressed

41 by a single indicator, potentially tranposable to human health

42

43 Keywords: noxiousness, integration, human health, ecosystem, chemotoxicity,

44 radiotoxicity 


\section{INTRODUCTION}

46 It is today consensually acknowledged that stressors occur usually in mixture in the

47 environment, and may impact simultaneously human and ecological health. This reality

48 generates for any living organism complex and uncertain exposure situations for which

49 potential health and ecological consequences are difficult to assess. Most often, the risk

50 assessment for human health is conducted independently, as well as the ecological risk

51 assessment, ignoring other risks (pyscho-social, politic, etc.). The awareness of this

52 situation by the general public result in a growing demand for risk integration that should

53 be reflected in regulatory developments. The notions underlying risk assessments are

54 changing to integrate this new dimension. This can only be done progressively, as it

55 supposes to concily concepts and methods specific to each domain involved as for

56 example within the TRIAD approach, the procedure recommended by the ISO for site-

57 specific ecological risk assessment of soil contamination (ISO, 2015).

58 At present, it is possible to deal operationally with the complex question of the

59 assessment of a global impact of pollutant mixtures. Effect models exist that would make

60 it possible with some improvements to grasp risks associated with the releases of

61 complex mixtures and subsequent exposure of plural targets in the environment. The

62 approach we propose here should be seen as a proof of concept for a framework to

63 characterize complex source terms for the environment through a unique noxiousness

64 indicator. This indicator aims to integrate in an harmonized way human health and

65 ecological aspects for two categories of toxicity, chemotoxicity and radiotoxicity. The

66 final objective is to obtain a unique operational indicator of the noxiousness of these 
67 complex source terms that would be a first-rate help for the management and

68 communication of the covered risks.

The Life Cycle Impact Asessessment (LCIA) approach provides a source of inspiration with regard to integration in terms of risks, and more specifically of ecological risks in freshwaters (ISO 2006a, 2006b). The corresponding indicator of ecosystem damages is the Potentially Affected Fraction (PAF) of species in the ecosystem, mostly obtained from a Species Sensitivity Distribution (SSD) (Pennington et al, 2004). The ms-PAF was developed as the next step to express the ecotoxic pressure of mixtures of substances (De Haes et al, 2002; Van de Meent and Huijbregts, 2005; Solomon et al, 2008). Based on a common toxic unit, this concept opens the door to ambitious integrative approaches. We took a first step in that direction in 2007 (Garnier-Laplace et al, 2009), looking for the assesment as a whole of the radioactive and chemical risks for fauna and flora exposed to liquid releases from nuclear facilities. We have recently deepened the principles of this approach (Beaumelle et al, 2017), with an investigation of the combined use of SSDs and additivity models. On the strength of these developments, we propose an operational method that produces additive indicators for both chemotoxicity and radiotoxicity, applied to human and ecological health. Our objective was to demonstrate the feasibility of an integrated single indicator for the global noxiousness of different stressors to which people and wildlife can be simultaneously exposed. We present first the construction of this indicator. We defined a toxicity factor Ftox as a simplification of the Effect Factor used in Life Cycle Impact Assessment, which relies for a given substance on its hazardous concentration for $50 \%$ of the species. This Ftox parameter is then combined with an information on the substance quantity to obtain a basic Noxiousness Indicator 
90 (NI). This has to be done without prior selection for each substance, each exposure

91 pathway, each toxicity endpoint. Basic NIs can be summed in different ways to produce

92 intermediate indicators, relevant for a category of toxicity, an exposure pathway or a

93 toxicity endpoint. A second level of integration is proposed to obtain the final indicator,

94 the global noxiousness indicator. In a second part we applied our approach to a High

95 Level radioactive Waste, a mixture of radionuclides and stable metals ideal to test our

96 indicator. The selection of substances was then done according to the availability of the

97 data required by the indicator calculation, our guideline being to privilege recognized and

98 homogeneous sources of data.

99 The framework presented in this paper to address the risk assessment of mixtures of

100 stable and radioactive substances for both man and the environment was conceived to

101 meet an operational need for comparison between complex source terms, i.e. in a purely

102 comparative perspective between related sources of toxicity. This main goal allowed

103 simplification in the processes taken into account; it required robust but overconservative

104 assumptions in order to achieve the integration which are not compatible with a realistic

105 risk assessment, but mainly answer the need for comparison. To enhance realism in the

106 selected scenarios, our method as presented here should be seen as a starting point to

107 develop a more consistent and homogeneous approach, within a collaborative process

108 associating experts from each domain.

\section{MATERIAL AND METHODS}

110 The method described hereafter was initially developed for ecosystems. Its extension to

111 human health was logically considered in a second time but is less accomplished. We 
112 considered its achievement will require the collaboration of experts and specialists in the

113 field of human toxicity. We decided to briefly present what we though to be the required

114 associated concepts and basics to invite beyond this feasability exercise the most suitable

115 audience to contribute to its improvement.

116 The detailed mathematical formulations of the factors and indicators presented below, as

117 well as the fully referenced data sources, are provided as supplemental data.

118

119

120

121

122

\subsection{Elementary bricks: Fate and Effect Factors}

Most of the method was described in a previous work (Garnier-Laplace et al, 2009).

Directly inspired from the LCIA methodology, it combines a fate-analysis step and an effect-analysis step respectively described by a fate factor (FF) and an effect factor (EF) (Pennington et al, 2006). These factors allow to express for each substance one-by-one the change in exposure from a given release and the change in effect per unit change of exposure. In summary, FF is defined per substance as the equilibrium ratio between the concentration within the receiving compartment and the concentration in the donor. EF is defined as the ratio $\Delta \mathrm{PAF}_{\mathrm{i}} / \Delta \mathrm{C}_{\mathrm{i}}$, also equal to the ratio $0.5 / \mathrm{HC}_{50 \mathrm{i}}$, where $\mathrm{HC}_{50 \mathrm{i}}$ is the Hazardous Concentration of the substance $i$ affecting 50\% of species at their $50 \%$ effect, as recommended to compare impact categories (Pennington et al, 2006). The variation in $\Delta \mathrm{PAF}$ is expressed as $0.5 \Sigma_{\mathrm{i}}\left(/ \Delta \mathrm{C}_{\mathrm{i}} / \mathrm{HC}_{50 \mathrm{i}}\right)$. Theories, assumptions and options related to the $\triangle \mathrm{PAF}, \mathrm{EF}$, their relationship and their use in a multi-stressor context have been presented and discussed elsewhere (e.g. Van de Meent et al, 2005 ; Garnier-Laplace et al, 2009).

The adaptation of the method to radionuclides needs to convert radiotoxicity data expressed in $\mu \mathrm{Gy} / \mathrm{h}$ into an $\mathrm{HC}_{50}$ expressed in $\mathrm{mol} / \mathrm{L}$, as for stable substances. The conversion process described by Garnier-Laplace et al (2009) is replicated. 
136 An additional step is taken toward the operational aspect of the method, by further

137 simplifying the EF expression. Focusing on comparisons, any proportionality factor

138 independent of the substance is useless and therefore removed. As such, we define a new

139 EF for ecosystems, called Toxicity Factor (Ftox) and simply equal to $1 / \mathrm{HC}_{50 \mathrm{i}}$.

140 Recognized practices in LCIA supported by available data prompt us to suggest the

141 extension of the approach to human health, considering ingestion and inhalation

142 exposures. The corresponding Ftox takes the form of the inverse of the ED $50_{\mathrm{i}, \mathrm{e}, \mathrm{v}}^{\text {whole life }}$.

143 This is the life dose inducing a 50\% increase of the probability to develop the pathology $e$

144 for individuals exposed to the substance $i$ via the pathway $v$ (kg internalized/ whole life).

145 This concept is shared between human radiotoxicity and chemotoxicity and should be

146 easily expressed in a common unit. But its use will require some care. For example, the

147 duration of what is similarly called "whole life", a shared notion used in the derivation of

$148 \mathrm{ED}_{50}$ values, differs slightly between chemotoxicity (70 years) and radiotoxicity (86

149 years). The issue of how comparable the various types of toxicity benchmarks (i.e. for

150 radioactive or stable substance) are, must also be solved. Some homogenization work

151 would also be probably necessary to obtain consistent datasets regardless the exposure

152 pathway (ingestion, inhalation) and the pathology (cancer, non-cancer).

153 2.3. The Noxiousness Indicator NI

154 The notion of Ftox lacks the quantitative dimension attached to the source term, which

155 introduction leads to the definition of the Noxiousness Indicator (NI). NI corresponds, for

156 a given substance $s$, to the product of its Ftox by its concentration $C_{i}$ in the source term 
under consideration i.e. the ratio of the substance concentration for example in water to its $\mathrm{HC}_{50}$. This dimensionless indicator can be summed for ecosystem on substances to give two basic indicators, either the radiological (NI-Erad) or chemical (NI-E $\left.\mathrm{E}_{\mathrm{chem}}\right)$ ecological noxiousness indicator. Summation over toxicity categories produces the final global indicator NI-E (Table 1). These three indicators allow dealing with two of the six impact categories selected (chemo- and radio-ecotoxicity).

The remaining four impact categories (human cancer and non-cancer effects due to chemotoxicity or radiotoxicity), remain to treat consistently. The previous approach has then been applied to human health in a similar however a bit more complex way. In addition to the category of effects (cancer; non-cancer) and type of toxicity (radiological; chemical) the noxiousness has to be characterised also with regard to exposures pathways. Indeed the $\mathrm{ED}_{50}$ values for people required by the method are usually reported for a given exposure pathway. A look in some relevant databases showed that data are easily available mainly for ingestion or inhalation. We ackownledged that other exposure pathways such as irradiation at distance or dermal adsorption could be of importance. However we considered that an objective of feasibility demonstration as pursued here could be satisfied by the immediate availability of ingestion and inhalation data. Moreover reducing the application to these two exposures pathways allowed a certain homogeneity in the data required for human and ecosystem health by using a same internationaly recognised source. That means finally that eight basic indicators with the same unit have to be produced to cover all the possible combinations (Table 1). These indicators might be aggregated to express the noxiousness in an integrated manner by summing some or all the individual indicators (all substances per effect category, all 
effects categories ...) or even the global noxiousness. Basically, each indicator NI-

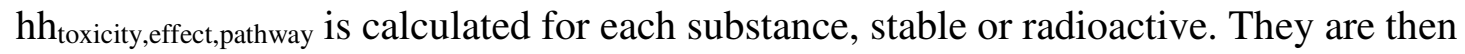
summed for all subtances in a toxicity category (chemo- or radiotoxicity) for a given exposure pathway and a given effect category to produce the eight basic indicators (i.e.

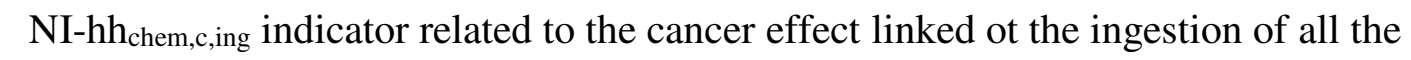
chemical substances). The first level of integration produces by summing over effects (cancer and non-cancer) four intermediate indicators that express the noxiousness related to an exposure pathway for a given category of toxicity (i.e.NI-hh $\mathrm{h}_{\mathrm{chem}}$, ing indicator related to the toxicity by ingestion of all chemicals), and by summing over exposure pathways four other indicators that express the noxiousness related to an effect category for the

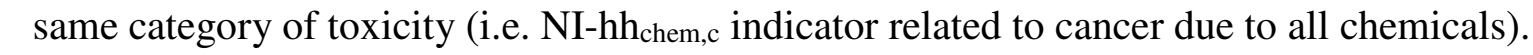
The second level of integration produces two indicators, one per category of toxicity (i.e. NI-hh $h_{\text {chem }}$ the indicator related to chemotoxicity including all effects and pathways). The third and last level of integration gives the final single expected indicator by summing the two previous ones.

The difficulty relies on ensuring the homogeneity of significance of all these indicators and expressing them in a same unit.

Table 1. Indicators proposed to characterize the noxiousness of complex source terms for human health (hh) and ecosystems (E), depending on the level of aggregation

\begin{tabular}{|c|c|c|c|c|c|}
\hline \multirow[b]{2}{*}{ Toxicity } & \multirow[b]{2}{*}{ Exposure pathway } & \multicolumn{3}{|c|}{ Human health } & \multirow{2}{*}{$\begin{array}{l}\text { Ecosystem } \\
\text { All effects }\end{array}$} \\
\hline & & $\begin{array}{l}\text { Cancer } \\
\text { (c) }\end{array}$ & $\begin{array}{l}\text { Non-cancer } \\
\text { (nc) }\end{array}$ & Both & \\
\hline \multirow{3}{*}{$\begin{array}{l}\text { Chemotoxicity } \\
\text { (chem) }\end{array}$} & Ingestion (ing) & NI-hh chem,c,ing & NI-hh chem,nc,ing & NI-hh $_{\text {chem,ing }}{ }^{\mathrm{a}}$ & n.a. \\
\hline & Inhalation (inh) & NI-hh chem,c,inh $_{\text {. }}$ & NI-hh ${ }_{\text {chem,nc,inh }}$ & NI-hh ${ }_{\text {chem,inh }}{ }^{a}$ & n.a. \\
\hline & All pathways & NI-hh ${ }_{\text {chem }, c^{a}}{ }^{a}$ & NI-hh chem,nc $_{\text {nc }}$ & NI-hh chem $^{b}$ & NI-E chem $^{b}$ \\
\hline
\end{tabular}




\begin{tabular}{|c|c|c|c|c|c|}
\hline \multirow{3}{*}{$\begin{array}{l}\text { Radiotoxicity } \\
\text { (rad) }\end{array}$} & Ingestion (ing) & NI-hh ${ }_{\text {rad,c,ing }}$ & NI-hh ${ }_{\text {rad,nc,ing }}$ & NI-hh ${ }_{\text {rad,ing }}{ }^{a}$ & n.a. \\
\hline & Inhalation (inh) & NI-hh ${ }_{\text {rad,c,inh }}$ & NI-hh ${ }_{\text {rad,nc,inh }}$ & NI-hh ${ }_{\text {rad,inh }}{ }^{\mathrm{a}}$ & n.a. \\
\hline & All pathway & NI-hh rad,c $^{a}$ & NI-hh ${ }_{\text {rad,nc }}{ }^{a}$ & NI-hh ${ }_{\text {rad }}{ }^{b}$ & NI-E ${ }_{\text {rad }}^{b}$ \\
\hline All toxicities & All pathways & NI-hh ${ }_{c}^{b}$ & NI-hh ${ }_{n c}$ b & NI-hh ${ }^{\mathrm{c}}$ & NI-E ${ }^{c}$ \\
\hline
\end{tabular}

${ }^{a}$ first level of aggregation (on effects or on pathways)

${ }^{\mathrm{b}}$ second level of aggregation (on a category of toxicity)

${ }^{c}$ third level of aggregation (all inclusive)

The proposed method does not aim to assess risk realistically, but rather to offer a comparison tool able to put on a same scale different impact categories initially not comparable. It relies on oversimplification of environmental transfer processes, exposure and effect characterizations (for example, use of $\mathrm{HC}_{50}$ rather than $\mathrm{HC}_{10}$ as usually in

206 ERA). The numerical values of the calculated indicators have no meaning in themselves, 207 they do not indicate a level of detriment or damage. They are only the product of a standardised rigourous approach applicable to any set of substances in a perfectly similar way, authorizing comparisons of noxiousness of various inventories of multiple

210 substances (or source-term) or for a given inventory of multiple substances, the time 211 evolution of the indicators.

\subsection{Data sources}

213 Toxicity data were collected from aknowledged sources for both human and ecosystems,

214 ensuring consistence by using as long as possible common supports. For chemicals, the 215 databases associated with the version 2.0 of the tool USETOX were then consulted for 216 humans $\left(\mathrm{ED}_{50}\right.$; Fantke et al, 2017) and ecosystems (EC ${ }_{50}$; Hugonnet et al, 2014). For 217 radionuclides, the FREDERICA database (Copplestone et al, 2008) and the derived 218 dose-effect relationships (Garnier-Laplace et al, 2010) underpinned the reasoning for 
ecosystems. For humans, data were retrieved from the UNSCEAR report (UNSCEAR, 1982) and the paper from Edwards and Lloyd (1998).

221 Data regarding the parameterisation of transfer in the environment were found in the ERICA Tool (Brown et al, 2008) specifically for wildlife and in some IAEA reports (IAEA, 2001, 2010) for humans. Additional information and details are provided as 224 supplemental data.

\section{APPLICATION AND DISCUSSION}

226 The proposed approach was applied to a well characterised source-term (High Level 227 radioactive Waste - HLW), including stable and radioactive substances, and its evolutionary composition at the short-, medium- and long-term $\left(0,10^{3}\right.$ and $10^{4}$ years $)$. Due to radioactive decay, the radiological toxicity of radionuclides initially present

230 decreases with time, by generating new substances that may themselves be radiologically 231 or chemically toxic.

232 According to Table 1, basic, intermediate and final noxiousness indicators were 233 calculated both for human health and ecosystems. The scarcity in (eco)toxicity data is a 234 well-known weakness of risk assessment methods since it concerns the vast majority of 235 chemical substances with the exception mainly of some metals (e.g. $\mathrm{Pb}, \mathrm{Hg}, \mathrm{Ni}$ ). Due to 236 the anticipated lack of data, especially for stable substances, the application focused on 237 the need for demonstration on the basis of freshwater ecosystems for which the greatest number of substances are characterised in terms of toxicity. For the human health aspect, the already identified limitations were not considered at this stage of method

240 development, but will have to be solved for an operational application. 
242 The objective was to evaluate comparatively the global noxiousness of the time

243 dependent compositions of the HLW (each of the three was considered as a different

244 waste for the study). We defined an intrinsic noxiousness, which is a property of a given

245 composition of the waste itself (inner waste toxicity), apart from any consideration of

246 dispersion in the environment. We defined additionally the in situ noxiousness, to

247 integrate the filter effect of environmental dispersion. This was done at first by

248 introducing in the calculation the liquid-solid partition coefficient. Both components of

249 noxiousness allow a more complete characterisation of the waste under investigation.

\subsection{Use of Noxiousness Indicators in isolation}

\subsubsection{Ecological indicators}

252 The ecological noxiousness indicators were calculated for any substance which

253 ecotoxicity was sufficiently documented. The resulting total intrinsic ecological NI

254 decreases by about two orders of magnitude over a million years (Figure 1).

255 Radiotoxicity is the major contributor over the full time period, the total chemotoxicity

256 being less by two to four orders of magnitude. Taking into account the chemotoxicity of

257 radionuclides and their stable decay products does not significantly alter the total

258 chemotoxicity, almost entirely due to stable substances initially present. The contribution

259 of stable substances generated by radioactive decay is not quantitatively significant. It

260 significantly increases over time, by two orders of magnitude over the studied period.

261 To illustrate the additional information possibly retrieved from such an approach, we

262 focused on the hierarchization of toxics, which may support management decision. We 
263 limited arbitrarily the toxic classification to the top ten substances in each category,

264 radiotoxic and chemotoxic substances. They have been prioritized with regard to their

265 contribution to the intrinsic ecological noxiousness of HLW from their noxiousness

266 indicators as a function of time. Initially from far the most harmful for wildlife (Figure

267 2A), radionuclides lose ranking places over time and their order or even their nature is

268 modified (e.g. ${ }^{243} \mathrm{Am}$ rises from ninth to second place, disappareance of ${ }^{137} \mathrm{Cs}$ ), due to

269 radioactive decay. After 1000 years, four metals ( $\mathrm{Al}, \mathrm{Ni}, \mathrm{Zn}$ and $\mathrm{Cr}$ ) integrate the first

270 half of the ranking (Figure2B), without change in their ranking. After 10000 years, the

271 top ten places are equitably occupied by radioactive (always the most harmful) and stable

272 substances (Figure2C), with order modification only for radionuclides. Intrinsic

273 noxiousness indicators range almost over two orders of magnitude, while they varied

274 initially over five orders of magnitude.

\subsubsection{Human health indicators}

276 When looking for completeness to calculate ecological noxiousness indicators, the

277 determination of human health indicators focused on a reduced number of substances.

278 The objective was clearly to demonstrate feasibility of an approach that would produce

279 consistent noxiousness indicators for humans and wildlife integrating chemo- and

280 radiotoxicity. The substances were selected among those for which both types of

281 indicators could be calculated.

282 Within the limit of the selected substances and under the assumptions made, the total

283 intrinsic chemical noxiousness of HLW does not evolve for human health over the

284 studied period of time (Figure 3). This indicator is mainly driven by cancer effects linked 285 to ingestion of substances, (inhalation is of minor contribution - results not shown). This 
noxiousness, initially up to four orders of magnitude lower than that of radiological harm,

287 remains lower for about 10,000 years. Effects mainly responsible for radiotoxicity would

288 be non-cancer effects, but differences between the two types of effect are much less

289 marked than for chemotoxicity (results not shown). As expected, results in terms of in

290 situ noxiousness would be similar, with a shift toward lowest values of indicators due to

291 the self-time filter effect. These observations have no absolute value; they depend closely

292 on the substances taken into consideration. This exercise has been done for illustrative

293 purposes only.

\subsection{Use of Noxiousness Indicators in combination}

295 Indicators were calculated for human health and ecosystems for the same source term

296 according to a harmonized approach, making them consistent. The next step would

297 logically to combine them to express the total noxiousness of this source term and

298 ultimately to compare several such terms. Multiple combinations are possible. The

299 simplicity of reading and interpretation guided the choice presented here. Both indicators

300 are reported on a single graph to allow categorization and immediate comparison of the

301 source terms. Each source-term is positioned according to its combination of indicators:

302 the human health indicator is plotted on the x-axis, the ecological indicator on the y-axis,

303 even though their values are not necessarily bound. Classes of noxiousness are defined as

304 the bands delimited by two successive pairs of identical values on the $\mathrm{x}$ and $\mathrm{y}$ axes (i.e.

305 band defined by $\mathrm{x}_{1}=\mathrm{y}_{1}=\mathrm{a}$ and $\mathrm{x}_{2}=\mathrm{y}_{2}=\mathrm{a}+1$ increment). Two source terms in the same class

306 (i.e. same band) have a comparable total intrinsic noxiousness. Two source terms in

307 different bands have different noxiousness the one in the right-most band being

308 considered more harmful. This representation offers the advantage of a great readibility, 
but supposes the implicit assumption of the equivalence between noxiousness for humans

310 and ecosystems for the same value of their respective indicators. This is questionable and

311 should be considered on a case-by-case basis, depending on the objective and context of

312 the noxiousness characterization. This issue could be solved by weighting one or the

313 other of the indicators. Then the question arises as to which weight values to apply...

314 Indicators were retrieved from the sets of results acquired for substances common to both 315 previous steps. We defined 14 classes of noxiousness covering the range of values of

316 total intrinsic noxiousness indicators for humans and ecosystems (Figure 4).

317 The decrease over time of the total intrinsic noxiousness indicators for the selection of

318 stable and radioactive substances from the HLW, already discussed, moves the waste

319 noxiousness from category XIII in the short term to category XI then VIII in the medium 320 and long terms respectively.

\section{4. CONCLUSIONS}

322 The proposed method was applied to the time changing composition of a High Level 323 radioactive Waste. Such a material includes both radionuclides and toxic metals, but is 324 today regulated only with regard to its radiotoxicity. Within the acknowledged limitations 325 of the approach, the global Noxiousness Indicator we calculated confirmed as expected 326 the dominance of this radiotoxicity through time over a period of 1 million years, for both 327 people and the environment. The use in combination of human health and ecological 328 indicators allowed to obtain a clear and synthetic view of the temporal evolution of the global noxiousness of the waste, which could be a powerful communication and decision

330 support. Lower levels of integration are also rich in insights, notably in terms of 
comparison between substances. This method is however largely perfectible, for example due to some "dead ends", data gaps, over simplification or huge uncertainties.

The concept of a single indicator of noxiousness for both human health and ecosystems, explicitly embedding radio- and chemotoxicity, is attractive and the related approach we presented appears promising. It illustrates the feasibility of full integration into a consistent approach related to human and ecosystem health. The reverse of the method is for chemicals at worst the well known lack of toxicity data, at best their heterogeneity. Effect endpoints, species, and other characteristics of lab tests devoted to $\mathrm{EC}_{\mathrm{x}}$ determination are extremely variable. Methods to obtain metadata from these basic

340 information are no longer homogeneous. The next step in the development of such

341 indicators would necessarily require signficant work to homogenize all the underlying 342 data. Additional consideration should be payed to bioavailability that conditions the 343 substance toxicity. The treatment of uncertainties has to be added. Solving these aspects

344 will produce truly consistent indicators, which use in combination will need an extra step 345 of normalization and weigthing. This finalization requires the involvment of all

346 stakeholders, especially when combining human and environmental health indicators.

\section{5. SUPPLEMENTAL DATA}

348 The Supplemental Data are available on the Wiley Online Library at 349 DOI:10.1002/etc.Xxx.

\section{REFERENCES} Beaumelle L., Della-Vedova C., Beaugelin-Seiller K., Garnier-Laplace J., Gilbin R. (2017). Ecological risk assessment of mixtures of radiological and chemical stressors : methodology to implement an msPAF approach. Environ. Pollut. 231 : 1421-1432. 
Brown, J.E., Alfonso, B., Avila, R., Beresford, N.A., Copplestone, D., Pröhl, G., Ulanovsky A. (2008). The ERICA Tool. J. Environ. Radioact., 99: 1371-1383. FREDERICA radiation effects database. J. Environ. Radioact., 99 : 1456-1463.

De Haes, U., Finnveden, G., Goedkoop, M., Hauschild, M., Hertwich, E., Hofstetter, P., 359 Jolliet, O., Klöpffer, W., Krewitt, W., Lindeijer, E., Müller-Wenk, R., Olsen, S., 360 Pennington, D.W., Potting, J., Steen, B. (2002). Life-Cycle Impact Assessment: Striving Towards Best Practice. SETAC PRESS, Brussels (Belgium). Edwards, A.A., Lloyd, D.C. (1998). Risks from ionising radiation: deterministic effects. J. Radiol. Prot. 18(3): 175-183.

364 Fantke, P. (Ed.), Bijster, M., Guignard, C., Hauschild, M., Huijbregts, M., Jolliet, O., 365 Kounina, A., Magaud, V., Margni, M., McKone, T.E., Posthuma, L., Rosenbaum, R.K., 366 van de Meent, D., van Zelm, R., (2017). USEtox ${ }^{\circledR} 2.0$ Documentation (Version 1), 367 http://usetox.org.

368 Garnier-Laplace J., Beaugelin-Seiller K., Gilbin R., Della-Vedova C., Jolliet O., Payet J. 369 (2009). A Screening Level Ecological Risk Assessment and ranking method for liquide 370 radioactive and chemical mixtures released by nuclear facilities under normal operating 371 conditions. Radioprotection 44(5): 903-908.

372 Garnier-Laplace, J., Della-Vedova, C., Andersson, P., Copplestone, D., Cailes, C., 373 Beresford, N.A., Howard, B. J., Howe, P., Whitehouse, P. (2010). A multi-criteria weight 374 of evidence approach for deriving ecological benchmarks for radioactive substances. $J$. 375 Radiological Prot., 30, 215-233 
376 Hugonnot O, Maillard E, Payet J (2015). AiiDA: an online database for sharing and 377 computing ecotoxicity data in the context of REACH. SETAC, Barcelona, 3-7 May 20.

378 IAEA (2001). Generic Models for Use in Assessing the Impact of discharges of 379 Radioactive Substances to the Environment. Safety Reports Series $n^{\circ} 19$, International 380 Atomic Energy Agency, Vienna, 117 p + annexes.

381 IAEA (2010). Handbook of Parameter Values for the Prediction of Radionuclide 382 Transfer in Terrestrial and Freshwater Environments. Technical Reports Series $n^{\circ} 472$, 383 International Atomic Energy Agency, Vienna, 208 p.

384 ISO (2006a). ISO14040: 2006- Environmental management -- Life cycle assessment -385 Principles and framework. 20 p.

386 ISO (2006b). ISO 14044:2006 Environmental management -- Life cycle assessment -387 Requirements and guidelines. $46 \mathrm{p}$.

388 ISO (2015). ISO DIS 19204 (E):2015 Soil Quality - Procedure for siste-speicif 389 ecological risk assessment of soil contamination (TRIAD approach). 22 p.

390 Pennington, D.W., Margni, M., Payet, J., Jolliet, O. Risk and regulatory hazard-based 391 toxicological effect indicators in life-cycle assessment (LCA). (2006). Human and 392 Ecological Risk Assessment 12 450-475.

393 Pennington, D.W., Payet, J. and Hauschild, M. (2004). Aquatic ecotoxicological 394 indicators in life-cycle assessment. Environ. Toxicol. Chem. 23 1796-1807.

395 Solomon, K.R., Brock, T.C.M., De Zwart, D., Dyer, S.D., Posthuma, L., Richards, S., 396 Sanderson, H., Sibley, P., Van den Brink, P.J. (2008). Extrapolation Practice for 
397 Ecotoxicological Effect Characterization of Chemicals. CRC Press, Boca Raton (Floride, 398 USA).

399 UNSCEAR (1982). Ionizing radiation: sources and biological effects. Report to the 400 General Assembly, Annex J: Non-stochastic effects of irradiation. United Nations, New 401 York (USA)

402 Van de Meent, D., Huijbregts, M.A.J. (2005). Calculating life-cycle assessment effect 403 factors from potentially affected fraction-based ecotoxicological response functions. $404 \quad$ Environ Toxicol Chem 24:1573-1578.

\section{FIGURE CAPTIONS}

407 Fig.1 temporal evolution of indicators of intrinsic ecological noxiousness of HLW, 408 depending on the stable or radioactive nature of the substances and their toxicity

409 Fig.2 temporal evolution of the ranking of the ten radionuclides and stable substances 410 within HLW the most inherently harmful to wildlife as a function of time 411 Fig.3 temporal evolution of indicators of intrinsic and in situ noxiousness for human 412 health of a selection of substances within HLW, depending on their toxicity 413 Fig.4 positioning of the selection of stable and radioactive substances from the HLW at 414 short, medium and long term in the abacus of total intrinsic noxiousness

415 Figure 1 


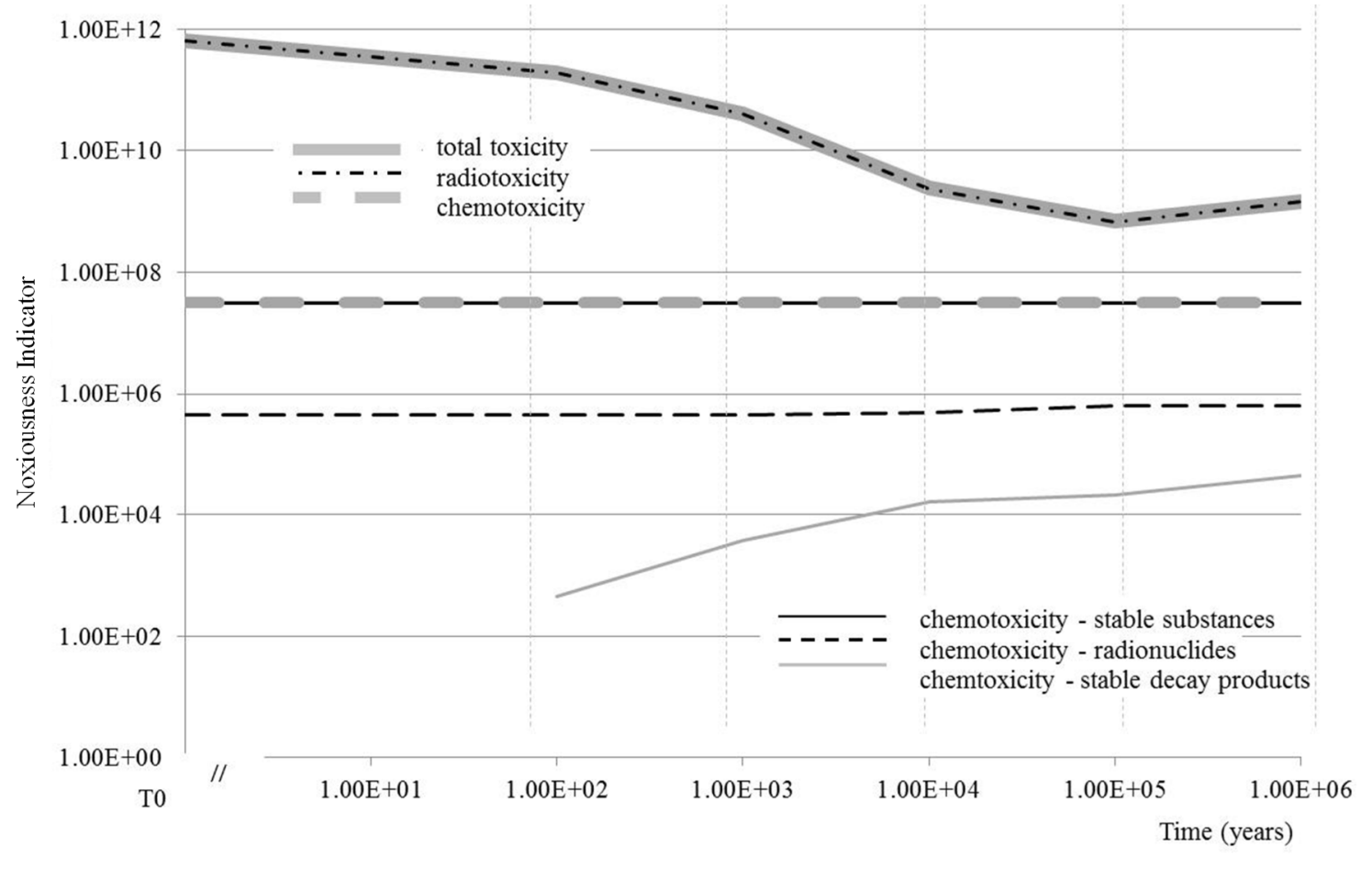


Figure 2

419

420

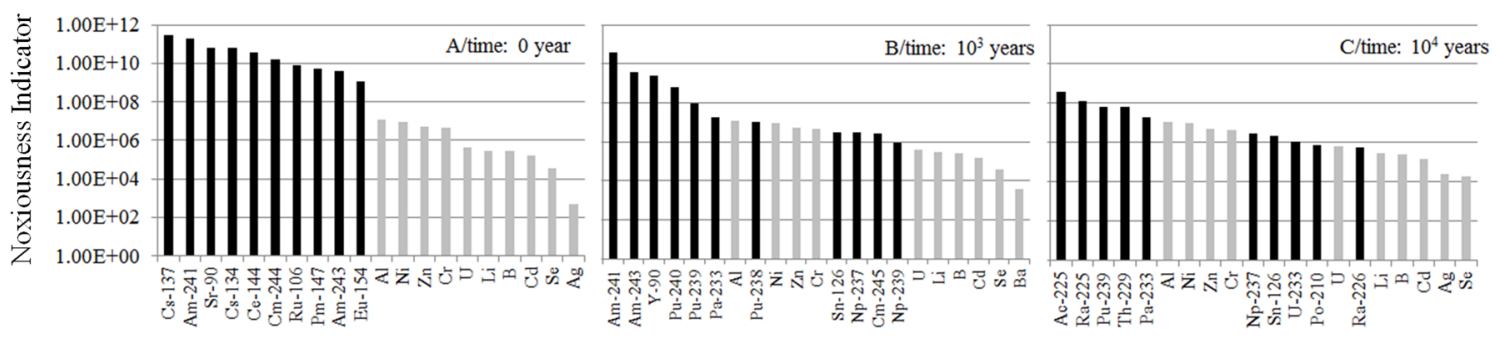

421 
Figure 3

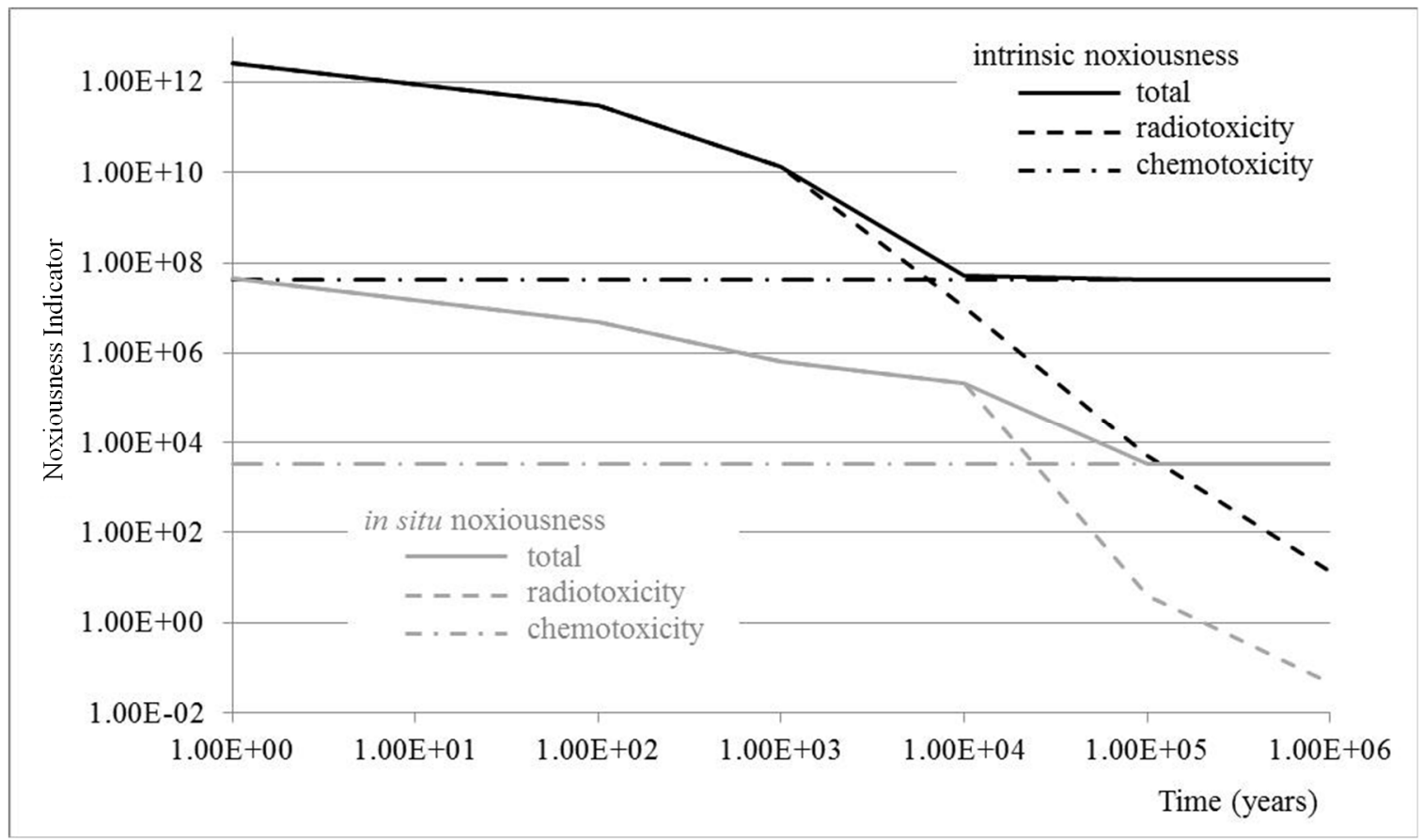

424 
Figure 4

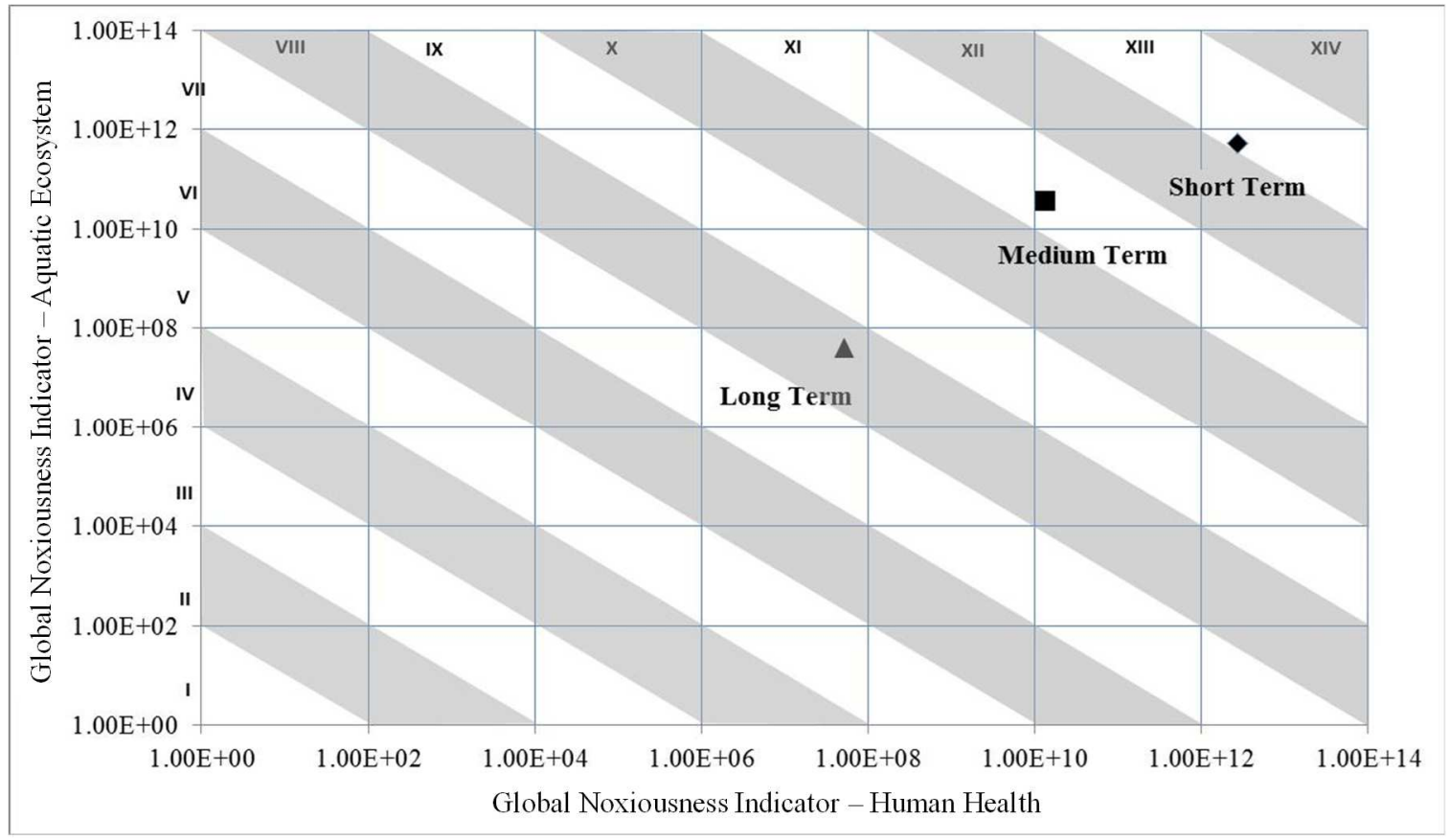




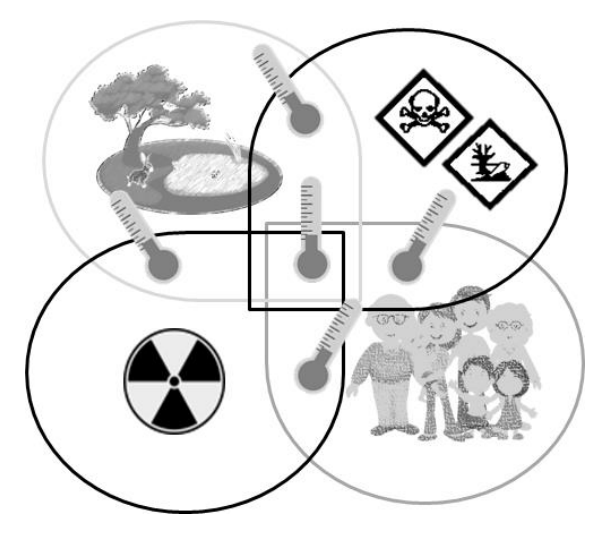

